Review

\title{
The Future of Clinical Islet Transplantation in the United States
}

Michael F Knoll ${ }^{1}$, Carmela A Knoll ${ }^{1}$, Rita Bottino ${ }^{1}$, Suzanne Bertera ${ }^{1,}{ }^{*}$, Massimo Trucco ${ }^{1,2}$

1. Institute of Cellular Therapeutics, Allegheny-Singer Research Institute, Allegheny Health Network, Pittsburgh, PA, USA; E-Mails: Michael.Knoll@ahn.org; Carmela.Knoll@ahn.org; Rita.Bottino@ahn.org; Suzanne.Bertera@AHN.org; Massimo.Trucco@ahn.org

2. Department of Biological Sciences, Carnegie Mellon University, Pittsburgh, PA, USA

* Correspondence: Suzanne Bertera; E-Mail: Suzanne.Bertera@AHN.org

Academic Editors: Kenneth L. Brayman and Preeti Chhabra

Special Issue: Islet Cell Transplantation

OBM Transplantation

2021, volume 5 , issue 1

doi:10.21926/obm.transplant.2101140
Received: January 12, 2021

Accepted: March 17, 2021

Published: March 25, 2021

\begin{abstract}
Clinical islet transplantation was first realized over four decades ago at the University of Minnesota. Autologous islet transplantation is now widely recognized as a treatment to prevent diabetes in patients after pancreas excision and is offered at major transplant centers throughout the United States and the world. Type 1 diabetes represents a much larger demographic in which islet transplantation may benefit patients. Allogeneic islet transplantation can now offer similar outcomes to pancreas transplantation in a subset of patients with labile type 1 diabetes with less risk than whole organ transplantation. It is recognized as a standard of care in nations around the world but not in the United States, despite the important developmental role US scientists and physicians have played. Early reports of islet transplantation focused on insulin independence that proved to diminish over time. However, regardless of insulin status, islet transplantation provides benefits ranging from improved quality of life to reduction in diabetic complications. A National Institutes of Health sponsored multi-center Phase 3 Clinical Trial (CIT-07) demonstrated safety and efficacy, although the Food and Drug Administration chose to consider islets as a biologic that requires licensure, which makes offering the procedure in the clinic very
\end{abstract}

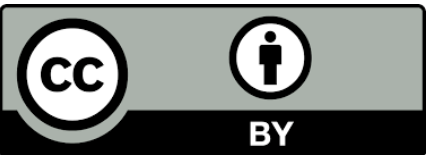

(C) 2021 by the author. This is an open access article distributed under the conditions of the Creative Commons by Attribution License, which permits unrestricted use, distribution, and reproduction in any medium or format, provided the original work is correctly cited. 
challenging. Until regulations can be brought into communion with international standards, allogeneic islet transplantation in the United States is unlikely to match international levels of success and once promising programs are left to wither on the vine. Food and Drug Administration approval would open the door for third party medical reimbursement and allow many patients the opportunity to enjoy better health and quality of life. Establishment of clinical islet transplantation for type 1 diabetes would lead to optimizations in procedures making it more efficacious and cost effective while offering support for ongoing islet xenotransplantation studies that could bring islet transplantation to even more patients.

\section{Keywords}

Allogeneic islet transplantation; autologous islet transplantation; cost-effectiveness of islet transplantation; type 1 diabetes; xenogeneic islet transplantation

\section{Introduction}

Many Americans would argue that the United States (US) provides access to the best healthcare in the world. Because of its reputation as a world leader in research and medicine, physicians come to the US for study and training, often returning home with valuable training and experience. As a result, the rest of the world is catching up and, in the utilization of clinical islet transplantation, surpassing us. The first clinical islet transplantation occurred in the US over four decades ago [1].

Since that time, the US has been a world leader in autologous islet transplantation (Tx) (i.e., in which the donor and recipient are the same) but has lagged behind the rest of the world in allogeneic islet Tx (i.e., islets from deceased human donors). While autologous islet Tx can help to prevent diabetes after pancreatic excision, allogeneic islet Tx has the potential to provide therapeutic relief to patients with difficult to control type 1 diabetes (T1D). Allogeneic islet transplantation is a standard of care treatment for patients with labile type 1 diabetes around the world, including Japan, the United Kingdom, Australia, and in much of continental Europe, and parts of Canada. In part based on the results of research and clinical trials conducted in the US, other nations have introduced their own islet transplantation programs. Figure 1 shows a representation of some of the similarities and differences between autologous and allogeneic islet Tx (see Figure 1). 


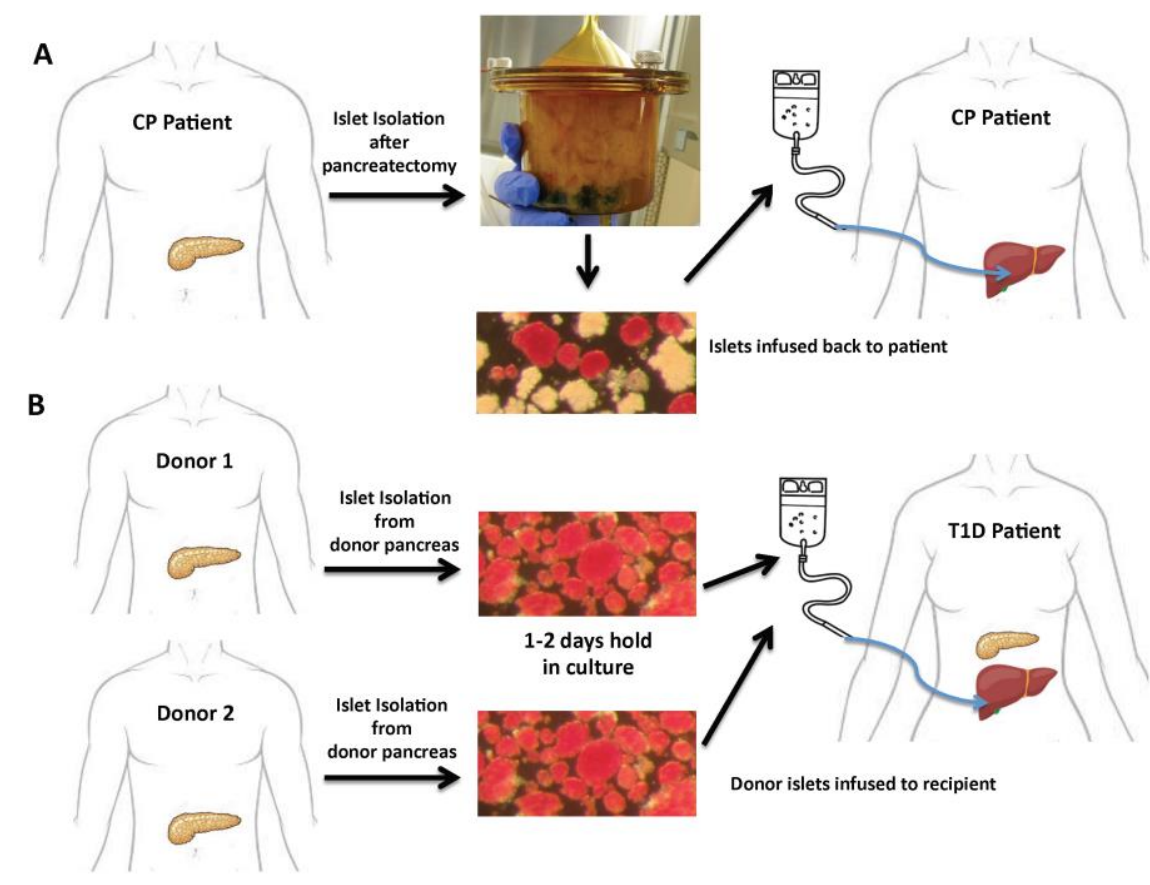

Figure 1 Comparison between autologous and allogeneic islet transplantation. A. A representation of autologous islet Tx for chronic pancreatitis (CP) patient. Pancreas is removed from patient; islets are isolated and returned directly to the patient without a period in culture. Islet purity is less of a priority and is a function of the volume of islets isolated for transplantation. Because the donor and recipient are the same, there is no need for immunosuppression. B. A representation of allogeneic islet Tx for T1D patient. Pancreata are removed from (usually) several deceased donors. The islets must meet purity and potency requirements before Tx. Islets are cultured typically for 1-2 days before Tx into a patient. Immunosuppression is necessary to prevent graft rejection.

Yet, twenty years after the initial success of the Edmonton Protocol, and despite the successful conclusion of the CIT-07 clinical trial instituted by the National Institutes of Health (NIH) to demonstrate its safety and efficacy, allogeneic islet transplantation is still considered an experimental approach to treat T1D in the US. This distinction limits access to a relatively few patients fortunate enough to be accepted into a clinical trial, contributes to the belief that islet $\mathrm{Tx}$ is ineffective, and reduces opportunities for research into alternative methods including islet xenotransplantation (xenoTx). Despite the success of autologous islet Tx, the fate of clinical islet Tx in the US likely rests with the regulation of allogeneic islet Tx by the Food and Drug Administration (FDA).

The United Network of Organ Sharing (UNOS) regulates the donation of pancreata for islet Tx in US-based clinical trials (i.e. CIT-07) under the same guidelines as pancreas Tx. Utilization of deceased donor pancreata for Tx is around $17 \%$ in the US [2], which is shockingly low considering the efforts that have been made to increase organ donation. In part, this may be due to an increase in less than optimal organs for Tx due to increasing donor age and obesity, factors that are negatively associated with successful outcomes in pancreas Tx [3]. However, donors that are less than optimal for pancreas Tx, including older donors and those with a $\mathrm{BMI}>30$, can still 
provide excellent islet yields for Tx [4]. Based on donor characteristics favoring one form of beta cell replacement over the other, there appears to be little direct competition for donor pancreata with an overlap of only $15 \%$ between the two ( $45 \%$ of donors suitable for islet Tx, $30 \%$ for pancreas Tx, and $40 \%$ for neither) [4]. Clinical acceptance of allogeneic islet Tx would lead to increased utilization rates for pancreas donors and reduce wasteful inefficiency. Since it is part of their mission to broaden organ availability and utilization, UNOS may have a role to play in discussions with the FDA in order to facilitate the advancement of well-regulated clinical islet Tx.

Reconsideration by the FDA to categorize allogeneic islet Tx as an organ Tx along the lines of its European counterparts instead of requiring a biologics license would be the first step in making the treatment available to many more patients who could benefit from islet transplantation.

\section{Autologous Islet Tx}

Autologous islet transplantation (AIT) can be applied after excision of the pancreas to mitigate the effects of surgically induced diabetes by returning to the patient their own insulin producing islet cells [5]. Immunosuppression is not necessary since the islet donor and recipient are the same. The first Clinical AIT following total pancreatectomy (TP) was successfully carried out at the University of Minnesota in 1977 [6]. Islet transplantation as part of a combined TPAIT is recognized around the world to be a standard of care for patient with unremitting and intractable pain from chronic pancreatitis (CP) that cannot be reduced by less invasive treatments. For this medical indication, third party insurance providers in the US consider AIT a reimbursable medical expense.

The Collaborative Islet Transplant Registry (CITR), which collects data from most islet Tx programs in the US, reported 754 AIT performed in North America (US Tx centers plus Edmonton, Canada) between 1999-2015 [7]. AIT can be carried out at the Tx center or at a remote islet isolation facility with either option demonstrating good therapeutic outcomes [8]. Our own islet isolation laboratory at the Institute of Cellular Therapeutics (Allegheny Health Network, Pittsburgh, USA) provides AIT for the University of Pittsburgh Medical Center (UPMC, Pittsburgh, USA) and as a remote isolation center for the Cleveland Clinic (Cleveland, USA), with Tx outcomes comparable to other major centers $[5,8,9]$. Full islet graft function characterized by insulin independence has been established in about $1 / 3$ of patients at three years post-Tx. About another third have partial graft function characterized by the need for some exogenous insulin intake [810]. TPAIT improves quality of life for patients with CP [8] while islet Tx specifically can improve quality of life for patients with diabetes [11].

The University of Minnesota remains one of the most active centers for autologous islet Tx in the world, and one of the few centers with the experience to perform the procedure on juveniles $[12,13]$. Cincinnati Children's Hospital has also published their findings from AIT carried out in children [14]. Our own group has provided autologous islets for 152 TPAITs since 2007, including 26 juvenile patients (under 18 years of age) as young as 7 years [9]. The trend towards TP and TPAIT can be observed in all geographical areas of the US [15]. Improvements to the procedure have resulted in better outcomes over time [16]. A multicenter Prospective Observational Study of TPAIT (POST) has recently begun in order to evaluate patient selection and timing of the procedure to maximize the benefit of islet Tx while eliminating CP pain [17]. Table 1 includes a list of Tx centers that take part in POST (see Table 1). Autologous islet transplantation remains a 
valuable tool as part of TPAIT; however, the prevalence of CP does not provide a large enough healthcare footprint to push forward clinical islet Tx in the US. Diabetes in general, however, presents a much larger healthcare challenge to meet in which we will need all of our therapeutic tools.

Table 1 US islet Tx centers.

\begin{tabular}{|c|c|c|c|c|}
\hline Participating Center & $\begin{array}{l}\text { AlloTx } \\
\text { Clinical Islet } \\
\text { Transplantation } \\
\text { (CIT) Consortium } \\
\text { (Hering et al.) }[19]^{a}\end{array}$ & $\begin{array}{l}\text { AutoTx [18] } \\
\text { Prospective } \\
\text { Observational } \\
\text { Study of TPAIT } \\
\text { (Bellin et al.) [17] }{ }^{\mathrm{b}}\end{array}$ & $\begin{array}{l}\text { AlloTx } \\
\text { Currently } \\
\text { recruiting for } \\
\text { clinical trials } \\
\text { (clinicaltrials.gov) } \\
\text { [20] }\end{array}$ & $\begin{array}{l}\text { AlloTx } \\
\text { Applied to } \\
\text { FDA for BLA }\end{array}$ \\
\hline $\begin{array}{l}\text { Baylor Simmons } \\
\text { Transplant Institute }\end{array}$ & & Yes - CITR & & \\
\hline $\begin{array}{l}\text { Cincinnati Children's } \\
\text { Hospital }\end{array}$ & & Yes - CITR & & \\
\hline $\begin{array}{l}\text { City of Hope Medical } \\
\text { Center }\end{array}$ & & & Yes & \\
\hline $\begin{array}{l}\text { Dartmouth-Hitchcock } \\
\text { Medical Center }\end{array}$ & & Yes - CITR & & \\
\hline $\begin{array}{l}\text { Emory University } \\
\text { John Hopkins Medical } \\
\text { Institutions }\end{array}$ & Yes - CIT & Yes - CITR & & \\
\hline $\begin{array}{l}\text { Massachusetts General } \\
\text { Hospital }\end{array}$ & Yes - CIT & & Yes & \\
\hline $\begin{array}{l}\text { Medstar Georgetown } \\
\text { Transplant Institute }\end{array}$ & & Yes & & \\
\hline $\begin{array}{l}\text { Northwestern } \\
\text { University }\end{array}$ & Yes - CIT & & & \\
\hline $\begin{array}{l}\text { Ohio State - Wexner } \\
\text { University Medical } \\
\text { Center }\end{array}$ & & Yes - CITR & & \\
\hline The Cleveland Clinic & & Yes - CITR & & \\
\hline $\begin{array}{l}\text { The Medical University } \\
\text { of South Carolina }\end{array}$ & & Yes - CITR & & \\
\hline University of Arizona & & Yes & & \\
\hline $\begin{array}{l}\text { University of California } \\
\text { San Francisco }\end{array}$ & Yes - CIT & & Yes & \\
\hline University of Chicago & & Yes - CITR & Yes & \\
\hline $\begin{array}{l}\text { University of Illinois at } \\
\text { Chicago }\end{array}$ & Yes - CIT & & & \\
\hline University of Miami & Yes - CIT & & Yes & \\
\hline $\begin{array}{l}\text { University of } \\
\text { Minnesota }\end{array}$ & Yes - CIT & Yes - CITR & & \\
\hline University of Nebraska & & Yes & & \\
\hline $\begin{array}{l}\text { University of North } \\
\text { Carolina }\end{array}$ & & Yes & & \\
\hline
\end{tabular}




\begin{tabular}{lllc}
\hline University of & Yes-CIT & & \\
Pennsylvania & & Yes - CITR & \\
University of Pittsburgh & & & Yes \\
Medical Center & & & Yes \\
University of Virginia & & Yes & \\
University of Wisconsin & Yes-CIT & & \\
Virginia Commonweath & Yes & & \\
University - Hume-Lee & & & \\
Transplant Center & &
\end{tabular}

${ }^{a} \mathrm{CIT}$ participant programs are identifiable by the mark "CIT" in the table. The CIT also includes international centers; University Hospital Rikshospitalet (Norway), University of Alberta (Canada), Uppsala University (Sweden), Karolinska University (Sweden).

${ }^{\mathrm{b}}$ POST includes nine original members and the more recently added Cleveland Clinic.

${ }^{c}$ Centers currently listed as providing autologous islet Tx as part of TPAIT on the Collaborative Islet Transplant Registry website are indicated by the mark "CITR" in the table [18].

\section{The Cost and Burden of Diabetes}

Diabetes represents an ongoing public health crisis. In the US alone, 34.2 million people (representing $>10 \%$ of the population) have diabetes [21]; with an economic burden of $\$ 327$ billion.

\subsection{Economic Burden of Type 1 Diabetes}

T1D accounts for only 5-10\% of all diabetes patients (still estimated to be several millions) but with the medical cost of T1D disproportionately higher than that [22]. High costs can be attributed to (i) earlier onset leading to longer durations of disease and (ii) requirements of regular maintenance (including blood glucose monitoring and daily insulin intake), as well as, (iii) longterm complications that arise from microvascular abnormalities exacerbated by hypo- and hyperglycemia [23]. These can include cardiovascular disease, kidney disease, diabetic retinopathy, and nerve damage [24]. Indirect costs must also be considered. Individuals with T1D are more likely to miss school days, less likely to graduate high school, more likely to miss workdays, and earn lower incomes than individuals without diabetes. Societal losses can be attributed to many factors including, (i) early mortality associated with T1D, (ii) physical disability, (iii) loss of productivity due to missing work, and, (iv) reduced performance while at work [23]. A report published in 2020 estimated the lifetime economic burden of T1D (including medical costs, and lost income and productivity) at $\$ 500,000$ per individual when compared to those without diabetes [25].

\subsection{Personal Burden of Type 1 Diabetes}

Beyond this, those not impacted by T1D often overlook the heavy psychological and social burden placed on individuals and families living with the disease [11]. T1D can be a much more intensive and personal battle than the more common type 2 diabetes (T2D). The need to constantly monitor caloric intake, physical activities, and blood glucose levels in order to calculate proper insulin doses can weigh heavily on patients. The need for so much control over every facet 
of their lives may take over at the expense of a normal life. Even the latest devices that can automatically adjust and provide an insulin dose require some education and effort to use properly. Overall, patients with T1D can expect to live 8-13 years less than healthy individuals [26].

A glycated hemoglobin level $(\mathrm{HbA} 1 \mathrm{c})$ of $<7.0 \%$ ( $53 \mathrm{mmol}$ per mole) is recommended for patients in order to reduce the risk of associated diabetic complications. However, only about $15 \%$ of patients taking insulin injections meet the recommended target level while more than $20 \%$ show poor glycemic control with $\mathrm{HbA1c}>8.8 \%$ putting them more at risk of severe hypoglycemic episodes and dangerous complications [27].

\subsection{Challenges of Hypoglycemia}

Fears of hypoglycemia are more commonly associated with T1D than other types of diabetes [28]. On average, T1D patients suffer from two hypoglycemic episodes per week with approximately one severe episode per year [29]. Severe hypoglycemic episodes requiring the action or assistance of another person may occur day or night and can result in seizures, altered consciousness, loss of consciousness, stroke, coma, or even in rare cases, death [28, 30]. As many as $10 \%$ of deaths attributed to T1D are due to hypoglycemia [29]. Episodes of hypoglycemia do not need to be frequent to be life endangering [31]. Anxieties over severe hypoglycemic episodes may lead patients to abandon plans for optimal glycemic control, allowing diabetes to worsen [11, 32]. Hypoglycemia is even more dangerous when accompanied by hypoglycemic unawareness that is a physiological inability to recognize the warning signs of an approaching episode. Patients with frequent hypoglycemic unawareness may not be able to maintain employment or an independent life-style [33].

The American Diabetes Association estimates that 1.3 million adults in the US have T1D with an additional 40,000 added each year [34]. It is not atypical for someone with T1D to experience hundreds of hypoglycemic episodes annually [29]. It has been estimated that approximately 1 out of every 3 individuals with T1D have impaired awareness of hypoglycemia and experience at least 1 severe hypoglycemic episodes per year [19]. Other estimates place the percentage who experience severe hypoglycemic events at $25 \%$ [35] or up to $40 \%$ [36].

Sudden unexplained nocturnal deaths that may result from overnight hypoglycemia categorized as "dead in bed" syndrome are particularly of concern to patients with diabetes and their families. Several small studies have shown that dead in bed syndrome may occur in $2-3 \%$ of patients $<50$ years of age with childhood onset of T1D [37, 38].

\section{Treatments for Type 1 Diabetes}

Exogenous insulin is the typical treatment for T1D. Most commonly, insulin is taken through daily injections; however, new delivery methods including closed loop "artificial pancreas" devices, so named because they attempt to mimic the rhythms of the endogenous endocrine system, can provide continual infusions. Exogenous insulin can be effective in reversing the immediate effects of diabetes but it cannot prevent secondary complications which account for much of the mortality and expense associated with T1D [39]. This led to renewed interest in beta cell replacement therapy. Either pancreas or islet Tx can offer the best option for therapeutic control of T1D. Due to limitations to both methods (i.e., morbidity associated with pancreas Tx and need for immunosuppression in both) these options have only been made available to 
patients with labile or brittle diabetes (i.e., characterized by dangerous episodes of hypoglycemia that cannot easily be controlled by standard exogenous insulin intake). Beta cell replacement (i.e.; pancreas or islet $\mathrm{Tx}$ ) and some intensive insulin therapies can mitigate secondary diabetic complications associated with excess morbidity and higher medical costs [24, 40,41], however, unlike beta cell replacement, insulin therapy has yet to demonstrate that it restores hypoglycemic unawareness or eliminates severe hypoglycemic episodes while maintaining blood glucose in a healthy range [19]. When the option is available, beta cell replacement offers the most effective treatment option due to its ability to resolve severe diabetes-related episodes, maintain tight glycemic control, and mitigate microvascular complications [40].

\subsection{Pancreas Transplantation}

The first pancreas transplantation was carried out at the University of Minnesota in 1966 [42]. Pancreas Tx is the current gold standard for labile T1D patients, although due to risks associated with the surgery and the need for immunosuppression, it is increasingly offered in conjunction with kidney $\mathrm{Tx}$ in patients with end-stage renal failure and diabetes. Transplantation of pancreas is more likely in conjunction with kidney Tx than alone (872 versus 143 respectively in 2019) [43]. Pancreas Tx can produce insulin independence, restore glycemic control, and delay diabetic complications such as cardiovascular disease, kidney failure, neuropathy, and diabetic retinopathy $[41,44]$. Drawbacks include morbidity and mortality associated with the invasive procedure and a lifetime need for immunosuppression that is characteristic of all allogeneic organ Tx [45]. Pancreas Tx is impractical in children due to limitations of adding the organ into their smaller gastrointestinal space. However, for the patient with difficult to control T1D and hypoglycemic unawareness, it can be a life saving and necessary medical intervention. For this subset of T1D patients, it is considered a standard of care and therefore covered by health insurance in the US and around the world.

Islet transplantation is based on the premise that the endocrine pancreas represents only 1-2\% of the pancreas volume and the insulin producing islet cells are all that is required in order to restore glycemic control [46]. Islet Tx is less invasive and now provides comparable outcomes to pancreas Tx [47]. It is also easier to carry out in children.

\subsection{Allogeneic Islet Transplantation}

The first clinical transplantation of allogeneic islets took place in 1974 [1] but it was not until the advent of the Edmonton Protocol several decades later that consistently successful outcomes were achieved. The initial report, published in the year 2000, showed that glycemic control was restored and all of the seven initial patients became insulin independent [48]. Results of the Edmonton Protocol spurred renewed interest in islet Tx as a therapy for T1D.

Allogeneic islet Tx shares several common features with pancreas Tx. Both require life-long immunosuppression to prevent the rejection of tissue donated by deceased human donors. Both can restore glycemic control, reverse hypoglycemic unawareness, eliminate severe hypoglycemic episodes, provide insulin independence, and delay or mitigate diabetic complications [31, 40, 41, 45]. While insulin independence proved not necessarily to be sustainable, evidence strongly suggests that circulating $\mathrm{C}$-peptide regardless of insulin status has a stabilizing effect on secondary diabetic complications $[49,50]$. 
The primary advantage of islet $\mathrm{Tx}$ is that it is a less invasive procedure that does not carry the excess morbidity and mortality associated with pancreas Tx. Islet Tx has less risk of complications and, due to these factors, may also be available to patients who would not be eligible for whole organ Tx (because of age or medical conditions). The primary disadvantage of islet Tx relative to pancreas Tx is the potential need for more than one organ to provide islets for Tx [33]. Often (but less frequently now than previously) islet infusions from two or more pancreata are required to establish metabolic control due to inefficiencies in islet isolation [16] (see Figure 1). Transplantation of $>5,000$ islet equivalents (IEQ)/kilogram of the recipient's body weight is associated with the desired metabolic control $[50,51]$. An IEQ is the standard estimate of islet volume based on the size of a hypothetical islet with a diameter of $150 \mu \mathrm{m}$ [9].

Perhaps the most salient feature that distinguishes allogeneic islet Tx (and pancreas Tx) from autologous islet Tx, is the need for immunosuppression to prevent rejection. Since the Edmonton Protocol, this typically includes tacrolimus and sirolimus $[19,48]$. However, both of these agents are toxic to islets and have unwanted diabetogenic effects $[52,53]$. New immunosuppressive cocktails have been introduced that are less toxic and able to prolong islet survival [16]. Despite these efforts, tacrolimus and sirolimus remain as part of most regimens for clinical allogeneic islet $\operatorname{Tx}[19,52]$.

\section{Status of Islet Transplantation around the World}

Autologous islet Tx as part of TPAIT is broadly recognized around the world as a standard of care for a subset of CP patients requiring pancreas excision. Internationally, many of the same Tx centers support allogeneic islet Tx as well. Despite its experimental status in the US, international surgeons have travelled to the US to be trained in the techniques of islet isolation and Tx and then setup islet programs in their homelands [50]. A substantial number of patients have undergone the procedure both in the US and around the world. CITR reported 1086 recipients of allogeneic islet Tx in North America (US Tx centers plus Edmonton) between 1999-2015 [7] but this number has dropped drastically in recent years due to the completion of clinical trials. Allogeneic islet Tx is considered a standard of care and is a reimbursable medical expense in Edmonton and parts of Canada, the United Kingdom, much of continental Europe, Australia, and Japan. Islet xenotransplantation (xenoTx), the transplantation of islets from one species into another species, will be discussed later in this report.

\subsection{Islet Transplantation in the US}

The National Institutes of Health established the Clinical Islet Consortium (CIT) to conduct clinical trials that would establish safety and efficacy of allogeneic islet Tx as a necessary prelude for licensure under guidelines established by the FDA [19]. The CIT consisted of 10 US transplant centers and 2 international centers. CIT-07 was a multicenter phase 3 clinical trial that enrolled and transplanted 48 subjects between 2007-2011. Table 1 includes a list of Tx centers belonging to the CIT (see Table 1). Subjects had T1D for at least five years, a history of at least one severe hypoglycemic episode in the previous year despite adherence to their medical care plan, and were unable to achieve glycemic control without hypoglycemic episodes $[11,19]$. Results of the trial published by Hering et al. in 2016 that showed $87.5 \%$ of subjects achieved primary outcome at one year $\left(\mathrm{HbA}_{1 \mathrm{c}}<7.0 \%\right.$ and freedom from severe hypoglycemic episodes) and $81 \%$ at two years. 
Insulin independence at one year was achieved by $52 \%$ of participants and maintained by $42 \%$ at two years [19]. Critics who deemed the trial less than a full success due to the lack of consistent and durable insulin independence missed the point of the study entirely as that was never the final goal. CIT-07 demonstrated that (i) optimized islet manufacturing methods and protocols can be established and carried out in multiple centers [54] and that; (ii), allogeneic islet Tx was safe and effective treatment for patients with labile T1D [19] that improved quality of life for patients [11]. Similar results have been reported in an Australian clinical trial as well [55] CIT-06, which evaluated safety and efficacy of islet Tx after kidney transplantation demonstrated similar success and no issues with kidney allograft stability [56]. These major clinical trials relied on tacrolimus for immunosuppression $[19,55,56]$ which is known to be toxic to islet cells, thus, even better results may be expected once better immunosuppressive agents can be found to replace them.

\subsection{Islet Transplantation around the World}

Interest in allogeneic islet transplantation was spurred in the US and around the world with the reported success of the Edmonton Protocol in 2000. In their initial report Shapiro et al. showed glycemic control was restored and all seven initial patients became insulin independent [48]. This compares starkly to the $9 \%$ rate of insulin independence up to 1999 [57]. In 2001, one year after the success of the Edmonton Protocol was reported, the government of Alberta, Canada began funding islet Tx at the University of Alberta Hospital as a standard of care therapy. Islet Tx is also available at the University of British Columbia in Vancouver which built on its experience as a pancreas Tx center [58].

In Europe, established centers copied Edmonton's methods and new centers were established. Collaborations were established between regional centers to facilitate islet Tx. The GRAGIL Network in Switzerland and France [59] and the Nordic Network in Finland, Norway, and Sweden $[60,61]$ are two prominent examples. The United Kingdom established the Islet Transplant Consortium (UKITC) to facilitate services for the UK [62].

Currently, two independent islet transplant programs exist in Italy, at the San Raffaele Scientific Institute and the Niguarda Hospital. The National Italian Transplant Centre coordinates islet transplantation in Italy [63]. Two independent islet Tx centers in Poland have lately been established at the Medical University of Warsaw, and as recently as 2018, the Medical University of Gdansk [64,65]. Support of colleagues in the US was crucial to the development of the program; including training of surgical team members in US islet transplant centers.

Australia offers a national "spoke and wheel" program modeled after the one in the UK in which islets are isolated at one of several centers before the patient is transplanted at a primary center $[55,66]$. Japan's transplantation programs have been slowed by traditions and values that do not favor widespread organ donation, however, as of April 2020, Japan now also offers islet Tx under national health services [52].

One thing that these international centers have in common is that services can be offered to appropriate patients either substantially or totally subsidized by national health programs [52, 59, $60,62-64,66]$.

\section{FDA Response to CIT-07}


In the US, several transplant centers coordinated their efforts in the $\mathrm{NIH}$-initiated CIT-07 clinical trial, standardizing all aspects of islet Tx from organ procurement, to islet isolation, and transplantation. This was the first phase 3 clinical trial of any therapy to demonstrate success in restoring both sustained normoglycemia and protection from severe hypoglycemic episodes in patients with long-standing T1D complicated by impaired awareness of hypoglycemia and who experienced severe hypoglycemic episodes. After publication of the results of CIT-07 in 2016, it was expected by many that FDA regulations would be adapted along the lines of its European counterparts, in which islet Tx is treated similarly to pancreas Tx, which would facilitate clinical adoption.

The FDA chose, instead, to consider islet transplantation as an extension of cellular drug therapy, requiring a biologics license application (BLA) for any center that wished to implement clinical allogeneic islet Tx. The underlying thought apparently in Europe (and elsewhere) is that the cells being transplanted are part of the pancreas, so the pancreatic islet cells would not necessarily require any additional regulation than is already required for organ Tx [64]. The FDA, however, chose to be cautious over concerns related to the variability of potency and purity of the islet product. Thus, many European transplant centers are able to offer islet transplantation to appropriate patients with T1D, while US centers would be required to subsidize substantial startup costs associated with the production standards required for FDA licensure [67].

\subsection{Costs of Manufacturing Allogenic Islets under FDA Guidance}

Unlike human islets designated for use in research, allogeneic islets for Tx are time-sensitive and, therefore, cannot be cryopreserved and commercialized. They must be produced or "manufactured" at the time of readiness for Tx (within a few days), based on the availability of the donor organ, the patient, and the surgical team and associates needed to carry out the procedure.

The FDA mandates that allogeneic islet isolation must be carried out in cGMP (current good manufacturing processes) facilities that are expensive to build and expensive to maintain. It has been previously estimated that construction of a cGMP facility could cost between \$1-7 million with an additional \$0.8-3 million annually to maintain it [68]. While many major transplant centers would already have GMP facilities available for use at a per hour rate, highly specialized islet isolation teams and materials would also be required. Dedicated cell processing facilities necessary for islet isolation are affiliated with hospitals and Universities; thus, they are already regulated and undergo multiple levels of oversight for their operation.

\subsection{Demonstrating Safety, Purity, and Potency}

In addition, transplant centers would be required to carry out testing to demonstrate safety, purity, and potency for each lot of islets and show that there are no clinically meaningful differences between the islet lot and a reference product. The FDA decision rests on the interpretation of islets as a cellular product similar to human stem cells that undergo change in culture and not as a component of the pancreas from which they are found. Accordingly, islets placed in culture must be strictly regulated to ensure that their characteristics remain true and no potentially dangerous changes occur. The alternative, practiced around the world, is to treat islets as part of the pancreatic organ and to not require additional regulation and testing than is required for pancreas Tx. Culturing allogeneic islets is what sets them apart from autologous islets 
that do not undergo any culture period before transplantation back into the patient. Nor, obviously, is culture applicable for whole pancreas Tx. Regulations are understandably strict when considering the possibility of stem cells or other types of cells to be modified in culture. Islets, however, are not placed in culture media in order to change their innate characteristics in any meaningful way. For islets, culture is simply a process to keep the cells "ready" for logistical reasons [33]. It may take several days for the patient to be transported to the center, and to undergo tests and initiate protocols including immune induction necessary for the overall success of the procedure. Circumstances regarding inefficiencies in islet isolation make it impractical to begin these other procedures without a period of waiting while the islets are cultured and the batch is verified to be acceptable for transplantation (i.e., measuring IEQ, viability, purity, and glucose stimulation are all potential methods of determining whether the islet batch meets release criteria). A period of culture can also allow the islets to recover from the stresses associated with islet isolation that are known to have a detrimental effect [33]. While in culture, dead islets and other tissue are eliminated, increasing purity but at the cost of islet volume available for transplantation. By some estimates, between $30-50 \%$ of islets are lost after culture $[69,70]$. Because islet quality and volume can impact chances for graft survival and function, this may be considered a test of product potency. However, culturing islets does not change the characteristic morphological properties of the islets themselves, which is surely the intent of the regulation, it only alters the number of functional cells transplanted into the recipient. While these regulations may be very necessary to insure the safety and potency for cells that are modified by culture [71, 72], islet cells are not of this type. European regulatory agencies have taken the opposite view from the FDA and regulate islet Tx in a similar manner to whole organ Tx, rather than a cellular product, thus, eliminating expensive and unnecessary controls while still providing requisite safety [64].

\subsection{The Impact of FDA Regulations on US Islet Transplant Programs}

The slow approach of the FDA guidance was perhaps justified when islet Tx was novel and much remained unknown. However, the preponderance of reports that establish the safety and efficacy both in the US and internationally makes the regulations seem onerous $[19,48,55,56,59$, $60,62,63,66,73-75]$. It is telling that none of the centers that took part in the NIH-initiated CIT-07 clinical trial has come forward in an attempt to secure a BLA to offer allogeneic islet Tx, despite these centers already having the existing infrastructure including GMP facilities, technical expertise, and networks of endocrinologists to select suitable candidates for islet Tx. Instead, as of 2020, allogeneic islet Tx in the US can still only be carried out in the context of a clinical trial. Only one Institute to the author's knowledge, the University of Virginia, has applied for a BLA for allogeneic islet Tx. With no incentive for third party health insurance companies to cover costs, few patients would be able to afford the treatment, making it impossible for transplant centers to sustain the cost of the BLA requirements themselves. According to the $10^{\text {th }}$ Annual Report published online by the Collaborative Islet Transplantation Registry, only four allogeneic islet Tx programs were active in the US as of 2015 with only 10 recipients in that year [7]. A search of Clinicaltrials.gov shows only about 8 programs actively recruiting subjects for allogeneic islet Tx in the US as of late 2020 [20]. FDA regulation has effectively stalled any meaningful attempt to offer 
allogeneic islet Tx to those who could benefit from the procedure and a contraction of financial support for clinical trials further limits its future.

\section{Costs, Cost Effectiveness, and Willingness to Pay}

Financial considerations play a role in the development and implementation of new medical procedures. Cost, cost-effectiveness, and willingness to pay for the benefit at a level of cost are all important in the decision-making process.

\subsection{Projected Cost of Allogeneic Islet Tx}

It can be difficult to estimate the costs associated with islet Tx since funding in the US is covered under clinical trials; (i), a fair market value for services does not exist, (ii) the cost of organ procurement can vary regionally and by organ procurement organization (OPO) [76]; (iii), fees for islet isolation and the use of GMP facilities vary by center; and (iv), multiple organs may be needed to achieve a therapeutic goal $[16,55]$. International reports placed the cost at about $\$ 70,000$ per infusion in Canada (about $\$ 54,000$ US dollars) [77] and less in France [78]. Even with rising costs since publication, these figures seem too low for the US. Perhaps these relatively modest costs are due to systems of organ procurement and payment schedules to comprehensive medical insurance boards that are not applicable to the US model. In any case, it is likely that the costs of medical procedures in the US are higher than in many other parts of the world. Immunosuppression represents one of the long-term costs associated with islet Tx and plays a major role in the overall expense of the procedure.

We can estimate the cost of allogeneic islet Tx using pancreas Tx as a model. UNOS has estimated the cost of pancreas transplantation in 2020 at close to $\$ 300,000$ [79]. A report published by Milliman Research placed the cost at $\$ 408,000$ [80]. This report did not calculate the cost of allogeneic islet Tx since it is not a standard of care therapy; however, it set the cost of pancreas procurement at $\$ 111,800$ or $27 \%$ of the total cost of pancreas Tx.

An analysis published in 2016 by Moassesfar et al. placed the cost of allogeneic islet Tx at substantially the same as pancreas $T x$ and this was true when considering either a single uncomplicated procedure or a second islet Tx [47]. A Canadian report concluded the same [77]. Expenses were greater for pancreas Tx (or unnecessary for islet Tx) in categories of operating room fees, anesthesia care, hospital room and nursing, medications, and miscellaneous costs. Islet Tx expenses included fees for interventional radiology, laboratory and imaging, use of GMP facility, and islet processing [47]. Islet Tx itself can represent about $30 \%$ of the cost [78].

This report, however, may not fully take into account expenses of failed islet isolations. Under the currently accepted guidelines established for CIT-07, islets used for transplantation must meet release criteria for IEQ/kg of the patient's body weight and purity. Using currently standardized procedures, islet isolation procedures typically fail to achieve these goals approximately half of the time. Thus, two pancreata may be needed to have one batch of islets for Tx. If two infusions are necessary the expense of pancreas procurement and islet isolation are doubled again. Pancreas procurement can cost upwards of $\$ 100,000$ per organ and reports from European centers estimate the costs of islet isolation at $30-35 \%$ of the cost of the entire procedure [78, 81]. The expenses attributed to the failure of islet isolation to provide islets for Tx and the need for multiple infusions can easily double the cost of islet Tx, perhaps as much as $\$ 600,000$ total. 
Fortunately, there is hope that the failure rate can be significantly reduced, as seen in data accrued with CIT-07 [55]. Likewise, there is a trend to better outcomes in transplantation with a single infusion $[7,16]$, which, together, will substantially lower costs.

While islet $\mathrm{Tx}$ can be expensive, the simplest scenario with one pancreata and one infusion may only cost half or even less than the maximum estimate. These absolute costs are not out of line compared to the costs of organ $\mathrm{Tx}[47,77]$. For comparison, the cost of several organ $\mathrm{Tx}$ procedures in the US can be found in Table 2 (See Table 2).

Table 2 Cost and cost effectiveness of whole organ and islet transplantation.

\begin{tabular}{|c|c|c|c|c|}
\hline Tx of organ or cells & $\begin{array}{l}\text { Cost }^{a} \\
\text { (US dollars) }\end{array}$ & $\begin{array}{l}\text { Quality adjusted } \\
\text { life years (QALY) } \\
\text { after Tx }\end{array}$ & Citation & $\begin{array}{l}\text { Cost/QALY b } \\
\text { (US dollars) }\end{array}$ \\
\hline $\begin{array}{l}\text { Kidney } \\
\text { (Living donor) }\end{array}$ & $\mathrm{n} / \mathrm{a}$ & $5.2-6.34$ & Axelrod et al. [82] & $\$ 39,939-80,486$ \\
\hline $\begin{array}{l}\text { Kidney } \\
\text { (Deceased donor) }\end{array}$ & $\$ 442,500$ & 6.53 & Knoll et al. [83] & $\$ 67,764$ \\
\hline Heart & $\$ 1,664,800$ & 7.67 & Long et al. [84] & $\$ 217,053$ \\
\hline Lung (single) ${ }^{c}$ & $\$ 929,600$ & $0.62-2.1$ & $\begin{array}{l}\text { Vasiladis et al. [85]; } \\
\text { Anyanwu et al. [86] }\end{array}$ & $\$ 442,667$ \\
\hline Liver & $\$ 878,400$ & 5.2 & Kensinger et al. [87] & $\$ 168,923$ \\
\hline Pancreas ${ }^{d}$ & $\$ 408,800$ & 14.7 & Schwartz et al. [88] & $\$ 27,810$ \\
\hline Pancreas-Kidney & $\$ 713,800$ & 9.09-10.0[\#] & Knoll et al. [83] & $\$ 71,380$ \\
\hline Islets e & $\$ 300-600,000$ & 10.9 & Beckwith et al. [89] & $\$ 27,523-55,046$ \\
\hline
\end{tabular}

a Cost of organ Tx represents average estimated billed charges for Tx in US in 2020 and is provided by Milliman, a provider of actuarial and related products and services. Cost of islet Tx is an estimate based on cost comparisons between islet and pancreas Tx [80].

${ }^{b}$ Calculated using the cost for organ Tx published by Milliman divided by QALY for organ Tx published by independent researchers.

${ }^{c}$ Cost of double lung Tx is estimated to be $\$ 1,295,900$.

d Pancreas Tx for diabetes is typically performed along with kidney Tx. Pancreas alone Tx is often indicated for pancreatic cancer which is reflected in the QALY scores for this table.

e Pancreas-kidney Tx for diagnosis of end-stage renal failure along with T1D.

${ }^{f}$ Cost of islet Tx is an estimate of what an uncomplicated procedure might cost based on costs associated with pancreas Tx; cost may be significantly higher if more than two pancreata are required to be processed for islets.

\subsection{Cost Effectiveness of Allogeneic Islet Tx}

Allogeneic islet Tx has been demonstrated to improve health and quality of life for patients with labile T1D, reduce the number of emergency room visits and hospital admissions, and to mitigate secondary diabetic complications. For these reasons, islet transplantation might be considered as a legitimate use of health care spending under the rule of rescue, the injunction to 
rescue identifiable individuals in immediate peril, regardless of cost [90]. The relatively high costs estimated to provide allogeneic islet $\mathrm{Tx}$ alone does not disqualify the procedure from the clinic because the cost of several types of organ Tx are significantly higher [80]. The cost of a single infusion with a high rate of success in islet isolation would be even less. However, allogeneic islet Tx must likely be seen as a cost-effective use of health care dollars before reaching wide-scale clinical utility. The addition of islet $T x$ to patients experiencing diabetes and already needing or having undergone kidney $\mathrm{Tx}$ is an even more reasonable measure since the expense and burden of immunosuppression are already necessary for the whole organ Tx.

A cost analysis in the US determined that allogeneic islet Tx was more effective and cost effective within 9-10 years compared to exogenous insulin treatment [89, 91]. A study out of the UK in 2015 confirmed these results, placing the range for cost-effectiveness at between 9-20 years. This is based on cost savings in treatment for diabetes, and mitigation of associated conditions including cardiovascular complications that counterbalance the expense of ongoing immunosuppression. Further improvements to islet isolation or engraftment would improve outcomes and make the procedure even more cost effective [92]. Absolute cost-effectiveness can be difficult to demonstrate however due to the variation in costs associated with the potential need for multiple organs. The good news is that there is a trend that favors islet Tx from a single donor [16]. Evidence provided from several clinical trials have demonstrated varied success rates for islet isolation from different centers. The overall islet isolation failure rate varies by center with the CIT-07 clinical trial reporting success rates between 24.3 and $89.5 \%$ giving hope that experience and best practices can improve the efficiency of islet isolation substantially and reduce costs accordingly. The same study reported that $47 \%$ of islet batches were transplanted as single dose to recipients. Improvements in engraftment will lead to the need for less pancreata as well. Costs for single donor islet tx may be lower than pancreas Tx given less complications expected following the procedure. This would support cost-effectiveness in the long run.

\subsection{Willingness to Pay}

A study conducted in Minneapolis determined that allogeneic islet Tx was cost effective compared to insulin therapy with a cumulative cost of $\$ 519,000$, a cumulative effectiveness of 10.9 Quality Adjusted Life years (QALY), and an average cost-effectiveness ratio of $\$ 47,800$ [89]. Savings in medical care from diabetic complications help to drive cost-effectiveness over the costs associated with immunosuppression. A similar study reported in Alberta, Canada argued that islet Tx was not cost effective for the treatment of T1D based on a willingness to pay threshold of up to $\$ 100,000$ per quality of adjusted life year.

Cost effectiveness studies such as these often utilize a threshold for stakeholders (i.e., insurance companies, etc.) willingness to pay set at $\$ 50-100,000$, however, a case can be made that the generally accepted willingness to pay threshold to evaluate novel therapies is arbitrary and antiquated [93]. Newer and perhaps fairer calculations for a threshold of willingness to pay can make a difference in calculations. The WHO suggests a threshold of up to $3 x$ the per capita annual income while others have proposed thresholds up to $\$ 300,000$ per QALY based on ever increasing healthcare costs and the benefits that have been observed from previous gains in healthcare [93]. Allogeneic islet Tx can be considered a cost-effective health care tool using these alternative thresholds of value. As time goes by, improvements in all facets of islet Tx procedure 
would lead to reduced costs and better outcomes meaning even more cost-effectiveness [94]. Studies such as these must be dependent on local costs and stakeholders willingness to pay the costs which explains their different findings [95]. Interesting to note, despite islet Tx not being found to be cost-effective in the Alberta study, allogeneic islet Tx is still offered to patients with the appropriate medical indication because it can provide better health outcomes to recipients regardless of cost.

Some whole organ Tx such as kidney are cost effective compared to alternative treatment (i.e., dialysis) over a lifetime, however, others, such as lung Tx, are not easily shown to be cost effective [85]. The benchmark for lung Tx is patient survival, the most important metric for determining access to medical procedures [96]. Thus, strict cost-effectiveness does not necessarily have to be the final arbitrator in a future clinical role for islet Tx. Lung Tx provides a mean QALY of 0.62 [85] compared to 10.9 for islet Tx [89].

\section{The Challenges of US Healthcare}

Many, if not most, of the nations with international islet Tx programs utilize single-payer national health insurance programs to fund medical care. The US healthcare system is made up of a patchwork of competing regional or national health insurance programs, often tied to hospital networks. Typically, an employer provides health care coverage to many Americans, making it difficult to select or alter coverage options. International opinion on the availability of Tx in the US often focuses on the expense (often significantly greater than in other nations) and lack of universal healthcare [97]. Often overlooked, however, is the role of the US government through its Medicare and Medicaid programs to function as a de facto single payer system for much of the population.

Medicare is a federally funded program that insures 44 million people over the age of 65 or roughly $13-18 \%$ of the entire population, with a yearly expenditure of 796.2 billion dollars. Medicaid is a state and federal program covering 72 million low-income or disabled persons with a yearly expenditure of 597.4 billion dollars. Of all medical expenses paid either by the patient or through any kind of insurance program, Medicare accounts for $21 \%$, Medicaid $16 \%$, and other government programs (including the Veterans Administration) 15\% of all medical expenditures in the US. Private healthcare remains the largest individual category of expenditure at $33 \%$, however, combined, the government programs account for over half of all medical spending. Medicare and Medicaid programs exert influence in medical care due to the guaranteed return to the service provider. Between these programs the US government provides healthcare for more people than many nations offering universal healthcare.

Diabetes and secondary complications associated with it, especially renal failure and cardiovascular disease, likely account for a large percentage of expenditures from these agencies. Once the experimental designation is removed, decision makers would be able to offer allogeneic islet $\mathrm{Tx}$ as an effective treatment for a substantial population and a cost-effective return on healthcare funding. Once federal programs accepted islet Tx for specific population of T1D patients, private healthcare insurance providers would, likely, follow suit.

\section{Potential Recipients of Allogeneic Islet Transplantation}


Organ Tx has long demonstrated its clinical effectiveness and is widely accepted while cellular transplantation seems to be considered "futuristic" and unobtainable. While islet Tx has been around for decades it has not achieved traction to enter public consciousness in the same way as kidney or heart Tx. This dichotomy may be explained by a perceived urgency for organ Tx that is not observed for islet Tx. Organ Tx necessitated by end-stage organ failure or other similarly drastic events is often only realized when life can be measured in months or a few years instead of in decades. T1D, on the other hand, is a slow killer. While diabetic ketoacidosis or hypoglycemia can lead to death with very little warning, standard insulin therapies can treat the majority of patients with T1D and they can live long lives despite the mortality associated with diabetes [26]. As the population ages, diabetic complications such as cardiovascular or kidney disease may take years before life-or-death consequences become apparent [24].

This lack of apparent urgency is compounded by a misconception that islet Tx is not a particularly successful treatment and that many patients would not gain insulin independence or would lose it over time; thus, the treatment may be considered a failure by those without complete understanding of the consequences of the disease or the efficacy of the treatment. Often the true benefits of islet Tx are not recognized or are willfully dismissed due to poor communication of their significance or other interests. Insulin independence (or lack there-of) hangs like an albatross around the neck of islet transplantation therapy but those with a fuller understanding of the benefits realize that it does not represent the full or even the most important effect of the treatment. Graft function, which has proven easier to achieve and more durable than insulin independence, is the more important consideration. Even in the absence of insulin independence, partial graft function can lead to (i), a reduction of exogenous insulin; (ii), elimination of hypoglycemia unawareness and substantial reduction of severe hypoglycemic episodes; (iii), mitigation of secondary diabetic complications; and (iv), better quality of life. No other therapeutic modality has demonstrated the benefits of allogeneic islet Tx along with the restoration of glycemic control to normal levels in the setting of a rigorous Phase 3 clinical trial [19].

Perhaps one day all patients with T1D and some with insulin dependent T2D might benefit from islet Tx. However, the benefits, costs, and potential risks including the need for immunosuppression required by the current protocols for clinical allogeneic islet Tx do not yet support islet Tx for these broad categories. However, international opinion indicates that the immediate benefit of islet Tx is best demonstrated in patients with labile or brittle T1D with hypoglycemic unawareness that experience severe hypoglycemic episodes that remain unresolved using exogenous insulin treatments. Based on the ADA estimate, upwards of 430,000 individuals experience these dangerous and potentially deadly conditions. Frontline therapies including realtime continuous glucose monitors, subcutaneous insulin infusion devices or insulin pumps, and education do not restore hypoglycemic awareness and may only resolve severe hypoglycemic episodes in about half of the individuals undergoing treatment $[19,98]$. This could leave as many as $108-216,000$ individuals in which severe hypoglycemia could not be resolved by standard/conventional treatments and that, therefore, might benefit from islet transplantation. In actuality, as in organ Tx and other medical procedures, other factors including costs and general health considerations would limit this subpopulation further. Patients experiencing diabetes and renal failure with the need for kidney Tx may also benefit from islet Tx since the burden of immunosuppression is already assumed with the kidney. 
Figure 2 shows an estimate of how many patients may benefit from islet Tx in the US compared to how many receive whole organ transplantation annually (see Figure 2).

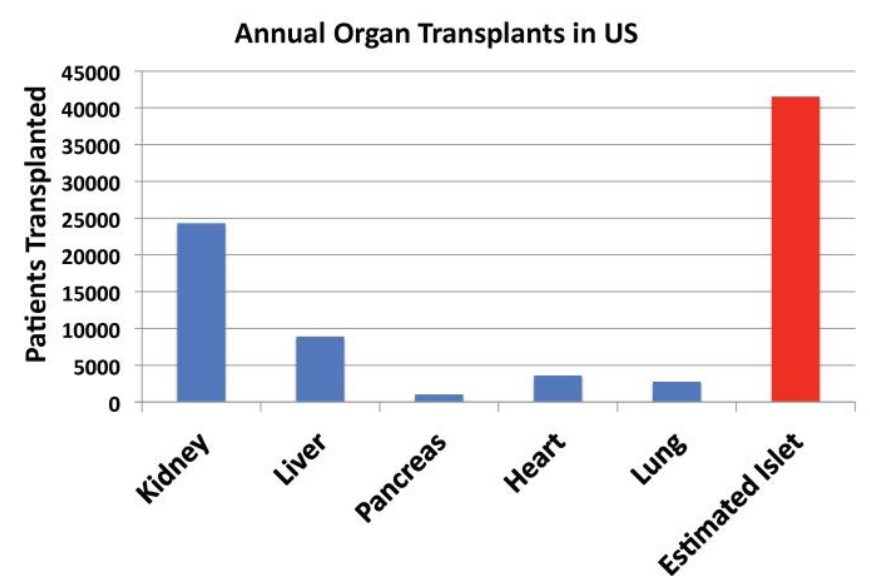

Figure 2 Comparison of potential islet transplant patients and annual organ transplants in the US. The number of kidney, liver, pancreas, heart, and lung transplants that were performed in the US in 2019 according to OPTN data compared to a 10 year estimate of the subset of patients with T1D in US who would benefit from islet Tx (based on how many people in the US are believed to have T1D and how often front-line treatments fail to relieve hypoglycemic episodes, pro-rated over a 10 year period)

Far from being a small group of potential beneficiaries, activity of this scope could soon overwhelm the organ donation system much the same way that has been seen with kidney Tx. Waitlists for organ transplantation exceeds 100,000 in the US [99]. With the estimated number of potential recipients, were allogeneic islet Tx to become reality in the US it would further incentivize efforts to better utilize pancreas donors, optimize islet isolation and transplantation procedures, and improve graft function. Efforts to bring clinical xenotransplantation to fruition would eliminate the bottleneck of pancreas donation. Combined with new and improved immunosuppressive agents, islet Tx may eventually be feasible for even more patients with T1D or some with insulin dependent T2D.

\section{Xenotransplantation}

The object of allogeneic islet Tx is not that it should be the first therapeutic option for all. For many patients, exogenous insulin and tight metabolic control can be effective. However, for the many patients for whom islet $\mathrm{Tx}$ is the most effective option, including those with the most lifethreatening forms of T1D, it would be beneficial to be able to offer the procedure in the US. As demand increases, the supply of pancreata suitable for islet isolation may eventually become inadequate. Xenotransplantation (xenoTx) of porcine organs such as kidneys has long been considered as a possibility to overcome the limitations placed on organ Tx by insufficient human donors to accommodate demand. Research into xenoTx has primarily been driven by long waiting lists for kidney Tx that currently include over 90,000 individuals [100] and adds 40,000 annually [99].

Likewise, porcine islets have been considered as a replacement for human pancreas donors for islet Tx [101]. Physiological differences among species, and particularly immunological 
incompatibilities, have led to sophisticated measures to produce pigs more compatible to humans [102]. Dr. Thomas Starzl, often considered "the father of modern transplantation" showed early interest in xenoTx [103] and was a proponent of genetic engineering of pig donors. Several authors of this report were part of the group that was responsible for the breakthrough

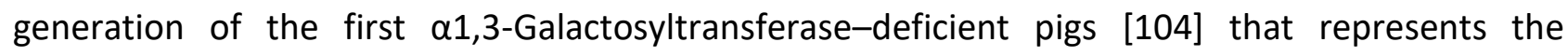
foundation of recent successful pre-clinical xenoTx. Our group has extensive experience in pig-tononhuman primate islet Tx models of diabetes [105-107]. We successfully demonstrated graft survival for a milestone of 1 year using genetically engineered pigs and repeated this success with multi-genetic pigs by adding various combinations of human transgenes [106, 107]. A South Korean group has demonstrated graft survival $>900$ days using unmodified wild-type pigs [108]. These pre-clinical results, however, have been possible due to the use of clinically unavailable immunosuppression based on anti-CD154mAbs [109].

Groth et al. performed the first clinical islet xenoTx in 1994 [110]. Neonatal porcine islets were transplanted into several patients with no ill effects but little to no therapeutic benefit. Since then, several clinical trials have taken place in Mexico [111], New Zealand and Argentina [112] but none in the US. Larger trials have been reported to have taken place in China and Russia as well [113]. These trials utilized encapsulation of the islets to "hide" them from the recipient's immune system in order to prevent rejection without the need for immunosuppression. Encapsulated islet Tx has demonstrated safety in humans while some trials have reported improvement in glycemic control to normal levels ( $\mathrm{HbA1c}<7.0 \%$ ) with a decrease in hypoglycemic unawareness [114]. An interesting solution to a difficult problem, encapsulation has floundered due to difficulties in consistently producing the materials for encapsulation that must let oxygen and nutrients in but keep cells and factors such as cytokines that would damage the islets out [114]. Clinical trials of non-encapsulated islets may be considered based on preliminary data on pig-to-nonhuman primate model produced at the University of Seoul. The impact of clinical approval of allogeneic islet Tx would likely spur increased funding and study of islet xenoTx in the US and around the world. The US is well situated for research into islet xenoTx due to the availability of cutting-edge biocompanies such as eGenesis that can produce the specialized genetically modified pigs for islet Tx [115] and the availability of nonhuman primates. Funding support for xenoTx in the US compares favorably with other leading nations [116] yet is extremely competitive. Funding for islet xenoTx remains problematic until allogeneic islet Tx itself is considered more than experimental. With the possibility of clinical islet Tx on the horizon and potential demand for donor pancreata increasing, it is likely that renewed efforts for islet xenoTx can overcome the challenges of encapsulation or immunosuppression more readily.

\section{Conclusions}

The future of clinical islet Tx in the US rests with the FDA. While autologous islet Tx is firmly established as a standard of care, the number of patients helped by islet Tx is small compared to the T1D population, and it will be allogeneic islet Tx that can drive growth in the field. While pancreas transplantation is considered as a gold standard treatment for labile T1D that cannot be resolved by standard or optimized exogenous insulin therapy, islet Tx offers similar outcomes as pancreas Tx with less risk. In this subpopulation, diabetes control is a matter of life and death. For this reason, many international regulatory agencies, but not the FDA, have chosen to consider 
allogeneic islet Tx under similar regulations as pancreas Tx. This has led to the development of islet Tx centers in close to a dozen nations. The US, however, continues to consider allogeneic islet Tx as an experimental procedure rather than a clinical treatment for T1D, despite recognizing autologous islet $\mathrm{Tx}$, a similar procedure used as part of a multifaceted treatment for chronic pancreatitis patients.

It is increasingly difficult to justify the distinction between transplanting autologous islets or allogeneic pancreas, both fully recognized under FDA guidance and reimbursable by third party insurances, and allogeneic islet Tx, which is neither. This is especially true with close to two decades of international experience demonstrating both safety and efficacy. In addition to denying an effective life-altering and potentially life-saving treatment to patients, experimental status also limits research into methods to enhance allogeneic islet transplantation making it more consistent and effective at producing optimal metabolic outcomes. A likely promising area of research would be the development of effective immunosuppressive agents to replace the diabetogenic agents tacrolimus and sirolimus that are the best option currently available but are toxic to islet cells [52]. A Similarly effective immunosuppression without these adverse effects would likely improve outcomes of allogeneic islet $\mathrm{Tx}$, even to the point of single donor procedures. Likewise, research into developing viable xenogeneic islet transplantation would be stimulated as well.

Reconsideration of the FDA position would be the first step in the US joining the growing international community that offers clinical allogeneic islet transplantation to selected patients with labile type 1 diabetes [117]. It would generate interest in optimizing pancreas donor selection, methods of islet isolation, immunosuppression, and research in xenoTx necessary to meet the healthcare challenges of the future. Most importantly, reconsideration of FDA guidelines and BLA requirements for islet Tx along the lines of those in Europe and elsewhere is necessary for the benefit of many patients with T1D.

\section{Abbreviations}

AIT = autologous islet transplantation

BLA = biologics license application

$\mathrm{CIT}=$ Clinical Islet Consortium

CITR = Collaborative Islet Transplant Registry

$\mathrm{CP}=$ chronic pancreatitis

TPAIT = total pancreatectomy followed by autologous islet transplantation

T1D = type 1 diabetes

UNOS = United Network of Organ Sharing

US = United States

XenoTx $=$ xenotransplantation

\section{Author Contributions}

MFK described planned and wrote the initial draft. CAK, RB, SB, and MT provided additional insights, critically reviewed, edited, and participated in drafting the final version of the manuscript. 


\section{Competing Interests}

The authors have declared that no competing interests exist.

\section{References}

1. Karl RC, Scharp DW, Ballinger W, Lacy P. Transplantation of insulin-secreting tissues. Gut. 1977; 18: 1062-1072.

2. Serrano OK, Vock DM, Dunn TB, Kandaswamy R, Finger EB. Maximizing utilization in pancreas transplantation: Phenotypic characteristics differentiating aggressive from nonaggressive transplant centers. Transplantation. 2018; 102: 2108-2119.

3. Schuetz C, Anazawa T, Cross SE, Labriola L, Meier RP, Redfield III RR, et al. $\beta$ cell replacement therapy: The next 10 years. Transplantation. 2018; 102: 215-229.

4. Berney T, Johnson PR. Donor pancreata: Evolving approaches to organ allocation for whole pancreas versus islet transplantation. Transplantation. 2010; 90: 238-243.

5. Arce KM, Lin YK, Stevens T, Walsh RM, Hatipoglu BA. Total pancreatectomy and islet cell autotransplantation: Definitive treatment for chronic pancreatitis. Cleve Clin J Med. 2016; 83: 435-442.

6. Najarian JS, Sutherland DE, Matas AJ, Steffes MW, Simmons RL, Goetz FC. Human islet transplantation: A preliminary report. Transplant Proc. 1977; 9: 233-236.

7. Collaborative Islet Transplantation Registry. CITR 10th Annual Report [Internet]. 2017 [cited 2020 Nov 17]. Available from: https://citregistry.org/content/reports-publicationspresentations.

8. Johnston PC, Lin YK, Walsh RM, Bottino R, Stevens TK, Trucco M, et al. Factors associated with islet yield and insulin independence after total pancreatectomy and islet cell autotransplantation in patients with chronic pancreatitis utilizing off-site islet isolation: Cleveland Clinic experience. J Clin Endocrinol Metab. 2015; 100: 1765-1770.

9. Bottino R, Bertera S, Grupillo M, Melvin PR, Humar A, Mazariegos G, et al. Isolation of human islets for autologous islet transplantation in children and adolescents with chronic pancreatitis. J Transplant. 2012; 2012: 642787.

10. Sutherland DE, Radosevich DM, Bellin MD, Hering BJ, Beilman GJ, Dunn TB, et al. Total pancreatectomy and islet autotransplantation for chronic pancreatitis. J Am Coll Surg. 2012; 214: 409-424.

11. Foster ED, Bridges ND, Feurer ID, Eggerman TL, Hunsicker LG, Alejandro R. Improved healthrelated quality of life in a phase 3 islet transplantation trial in type 1 diabetes complicated by severe hypoglycemia. Diabetes Care. 2018; 41: 1001-1008.

12. Bellin MD, Forlenza GP, Majumder K, Berger M, Freeman ML, Beilman GJ, et al. Total pancreatectomy with islet autotransplantation resolves pain in young children with severe chronic pancreatitis. J Pediatr Gastroenterol Nutr. 2017; 64: 440-445.

13. Wilhelm JJ, Balamurugan AN, Bellin MD, Hodges JS, Diaz J, Jane Schwarzenberg S, et al. Progress in individualizing autologous islet isolation techniques for pediatric islet autotransplantation after total pancreatectomy in children for chronic pancreatitis. Am J Transplant. 2020; 21: 776-786.

14. Bondoc AJ, Abu-El-Haija M, Nathan JD. Pediatric pancreas transplantation, including total pancreatectomy with islet autotransplantation. Semin Pediatr Surg. 2017; 26: 250-256. 
15. Lara LF, Bellin MD, Ugbarugba E, Nathan JD, Witkowski $P$, Wijkstrom $M$, et al. A study on the effect of patient characteristics, geographical utilization, and patient outcomes for total pancreatectomy alone and total pancreatectomy with islet autotransplantation in patients with pancreatitis in the United States. Pancreas. 2019; 48: 1204-1211.

16. Balamurugan AN, Naziruddin B, Lockridge A, Tiwari M, Loganathan G, Takita M, et al. Islet product characteristics and factors related to successful human islet transplantation from the collaborative islet transplant registry (CITR) 1999-2010. Am J Transplant. 2014; 14: 2595-2606.

17. Bellin MD, Abu-El-Haija M, Morgan K, Adams D, Beilman GJ, Chinnakotla S, et al. A multicenter study of total pancreatectomy with islet autotransplantation (TPIAT): POST (Prospective Observational Study of TPIAT). Pancreatology. 2018; 18: 286-290.

18. CITR. North American islet transplant centers [internet]. [cited 2021 February 8th]. Available from: https://citregistry.org/na-islet-transplant-centers.

19. Hering BJ, Clarke WR, Bridges ND, Eggerman TL, Alejandro R, Bellin MD, et al. Phase 3 trial of transplantation of human islets in type 1 diabetes complicated by severe hypoglycemia. Diabetes Care. 2016; 39: 1230-1240.

20. ClinicalTrials.gov. Bethesda, MA: National Institutes of Health. [cited 2020 November 17th]. Available from: https://clinicaltrials.gov/ct2/results?recrs=ab\&cond=Type+1+Diabetes\&term=islets\&cntry=US \&state $=$ \&city $=$ \&dist $=$.

21. Centers for Disease Control and Prevention. National diabetes statistics report, 2020. Atlanta, GA: Centers for Disease Control and Prevention, U.S. Dept of Health and Human Services; 2020.

22. American Diabetes Association. Economic costs of diabetes in the U.S. in 2017. Diabetes Care. 2018; 41: 917-928.

23. Tao B, Pietropaolo M, Atkinson M, Schatz D, Taylor D. Estimating the cost of type 1 diabetes in the US: A propensity score matching method. PLoS ONE. 2010; 5: e11501.

24. Atkinson MA, Eisenbarth GS, Michels AW. Type 1 diabetes. Lancet. 2014; 383: 69-82.

25. Sussman M, Benner J, Haller MJ, Rewers M, Griffiths R. Estimated lifetime economic burden of type 1 diabetes. Diabetes Technol Ther. 2020; 22: 121-130.

26. DiMeglio LA, Evans-Molina C, Oram RA. Type 1 diabetes. Lancet Lond Engl. 2018;391: 24492462.

27. Lind $M$, Svensson A-M, Kosiborod $M$, Gudbjörnsdottir S, Pivodic A, Wedel $H$, et al. Glycemic control and excess mortality in type 1 diabetes. N Engl J Med. 2014; 371: 1972-1982.

28. Liu J, Bispham J, Fan L, Poon J-L, Hughes A, Mcauliffe-Fogarty A, et al. Factors associated with fear of hypoglycaemia among the T1D exchange Glu population in a cross-sectional online survey. BMJ Open. 2020; 10: e038462.

29. Cryer PE. Hypoglycemia in type 1 diabetes mellitus. Endocrinol Metab Clin. 2010; 39: 641-654.

30. Frier BM. How hypoglycaemia can affect the life of a person with diabetes. Diabetes Metab Res Rev. 2008; 24: 87-92.

31. Cryer PE. Severe hypoglycemia predicts mortality in diabetes. Diabetes Care. 2012; 35: 18141816.

32. Shepard JA, Vajda K, Nyer M, Clarke W, Gonder-Frederick L. Understanding the construct of fear of hypoglycemia in pediatric type 1 diabetes. J Pediatr Psychol. 2014; 39: 1115-1125.

33. Mittal S, Johnson P, Friend P. Pancreas transplantation: Solid organ and islet. Cold Spring Harb 
Perspect Med. 2014; 4: a015610.

34. Healthline. Diabetes: Facts, statistics, and you [Internet]. 2018 [cited 2021 January 5th]. Available from: https://www.healthline.com/health/diabetes/facts-statistics-infographic.

35. Forbes S, McGowan NW, Duncan K, Anderson D, Barclay J, Mitchell D, et al. Islet transplantation from a nationally funded UK centre reaches socially deprived groups and improves metabolic outcomes. Diabetologia. 2015; 58: 1300-1308.

36. McCall AL. Insulin therapy and hypoglycemia. Endocrinol Metab Clin. 2012; 41: 57-87.

37. Ramsli HM, Therkelsen SP, Søvik O, Thordarson H. [Unexpected and unexplained deaths among young patients with diabetes mellitus]. Tidsskr Prakt Med Ny Raekke. 2004; 124: 30643065.

38. Secrest AM, Becker DJ, Kelsey SF, Laporte RE, Orchard TJ. Characterizing sudden death and dead-in-bed syndrome in type 1 diabetes: Analysis from two childhood-onset type 1 diabetes registries. Diabet Med. 2011; 28: 293-300.

39. Schuetz C, Markmann JF. Islet cell transplant: Update on current clinical trials. Curr Transplant Rep. 2016; 3: 254-263.

40. Bellin MD, Dunn TB. Transplant strategies for type 1 diabetes: Whole pancreas, islet and porcine beta cell therapies. Diabetologia. 2020; 63: 2049-2056.

41. Gremizzi C, Vergani A, Paloschi V, Secchi A. Impact of pancreas transplantation on type 1 diabetes-related complications. Curr Opin Organ Transplant. 2010; 15: 119-123.

42. Sutherland DER, Gruessner RWG, Dunn DL, Matas AJ, Humar A, Kandaswamy R, et al. Lessons learned from more than 1,000 pancreas transplants at a single institution. Ann Surg. 2001; 233: 463-501.

43. Organ Procurement and Transplantation Network. National Data - OPTN - Organs transplanted by organ type [Internet]. OPTN - Organs transplanted by organ. [cited 2020 November 6th]. Available from: https://optn.transplant.hrsa.gov/data/view-data-reports/national-data/.

44. Bottino R, Trucco M. Clinical implementation of islet transplantation: A current assessment. Pediatr Diabetes. 2015; 16: 393-401.

45. Ryan EA, Bigam D, Shapiro AM. Current indications for pancreas or islet transplant. Diabetes Obes Metab. 2006; 8: 1-7.

46. Hart NJ, Powers AC. Use of human islets to understand islet biology and diabetes: Progress, challenges and suggestions. Diabetologia. 2019; 62: 212-222.

47. Moassesfar S, Masharani U, Frassetto LA, Szot GL, Tavakol M, Stock PG, et al. A comparative analysis of the safety, efficacy, and cost of islet versus pancreas transplantation in nonuremic patients with type 1 diabetes. Am J Transplant. 2016; 16: 518-526.

48. Shapiro AM, Lakey JR, Ryan EA, Korbutt GS, Toth E, Warnock GL, et al. Islet transplantation in seven patients with type 1 diabetes mellitus using a glucocorticoid-free immunosuppressive regimen. N Engl J Med. 2000; 343: 230-238.

49. Thompson DM, Meloche M, Ao Z, Paty B, Keown P, Shapiro RJ, et al. Reduced progression of diabetic microvascular complications with islet cell transplantation compared with intensive medical therapy. Transplantation. 2011; 91: 373-378.

50. Shapiro AM. Strategies toward single-donor islets of Langerhans transplantation. Curr Opin Organ Transplant. 2011; 16: 627-631.

51. Wang $\amalg$, Kin T, O'Gorman D, Shapiro AM, Naziruddin B, Takita M, et al. A multicenter study: North American islet donor score in donor pancreas selection for human islet isolation for 
transplantation. Cell Transplant. 2016; 25: 1515-1523.

52. Takaki T, Shimoda M. Pancreatic islet transplantation: Toward definitive treatment for diabetes mellitus. Glob Health Med. 2020; 2: 200-211.

53. Triñanes J, Rodriguez-Rodriguez AE, Brito-Casillas $Y$, Wagner $A$, De Vries AP, Cuesto $G$, et al. Deciphering tacrolimus-induced toxicity in pancreatic $\beta$ cells. Am J Transplant. 2017; 17: 28292840.

54. Ricordi C, Goldstein JS, Balamurugan AN, Szot GL, Kin T, Liu C, et al. National institutes of health-sponsored clinical islet transplantation consortium phase 3 trial: Manufacture of a complex cellular product at eight processing facilities. Diabetes. 2016; 65: 3418-3428.

55. O'Connell PJ, Holmes-Walker DJ, Goodman D, Hawthorne WJ, Loudovaris T, Gunton JE, et al. Multicenter Australian trial of islet transplantation: Improving accessibility and outcomes. Am J Transplant. 2013; 13: 1850-1858.

56. Markmann JF, Rickels MR, Eggerman TL, Bridges ND, Lafontant DE, Qidwai J, et al. Phase 3 trial of human islet-after-kidney transplantation in type 1 diabetes. Am J Transplant. 2020. Doi: 10.1111/ajt.16174.

57. Bruni A, Gala-Lopez B, Pepper AR, Abualhassan NS, Shapiro AJ. Islet cell transplantation for the treatment of type 1 diabetes: Recent advances and future challenges. Diabetes Metab Syndr Obes Targets Ther. 2014; 7: 211-223.

58. Warnock GL. Improved human pancreatic islet isolation for a prospective cohort study of islet transplantation vs best medical therapy in type 1 diabetes mellitus. Arch Surg. 2005; 140: 735744.

59. Benhamou PY, Oberholzer J, Toso C, Kessler L, Penfornis A, Bayle F, et al. Human islet transplantation network for the treatment of type I diabetes: First data from the Swiss-French GRAGIL consortium (1999-2000). Diabetologia. 2001; 44: 859-864.

60. Lundgren T, Korsgren O, Foss A, Felldin M, Källén R, Salmela K, et al. The Nordic network for clinical islet transplantation - islet after kidney (IAK)-results and experiences from the first 44 transplantations. Transplantation. 2004; 78: 178.

61. Nordic Islets. Clinical islet transplantation [Internet]. [cited 2020 November 10th]. Available from: https://nordicislets.medscinet.com/en/clinical-islet-transplantation.aspx.

62. Johnson PR, UK Islet Transplant Consortium (UKITC) on behalf of the. Islet transplantation in the UK. CellR4. 2019; 7: e2788.

63. Bertuzzi F. Islet transplantation in Italy. CellR4. 2019; 7: e2772.

64. Dębska-Ślizień A, Wszoła M, Bachul P, Gulczyński J, Żygowska I, Berman A, et al. Islet transplantation-perspective from poland. CellR4. 2019; 7: e2786.

65. Wszoła M, Kwiatkowski A, Berman A, Górski $Ł$, Chmura A. Islet transplantation as a treatment for complications of type I diabetes. Pol Merkur Lek Organ Pol Tow Lek. 2013; 35: 127-132.

66. O'Connell PJ, Kay TW. Establishing a national program of islet transplantation in Australia. CellR4. 2019; 7: e2797.

67. Ricordi C, Japour A. Transplanting islet cells can fix brittle diabetes. Why isn't it available in the US? CellR4. 2019; 7: e2768.

68. Ng NH, Tan W, Koh YX, Teo A. Human islet isolation and distribution efforts for clinical and basic Research. OBM Transplant. 2019; 3: 31.

69. Bottino R, Bertera S, Knoll C, Knoll MF, Trucco M. Human islet isolation: Status and future considerations. CellR4. 2019; 7: e2607. 
70. Noguchi H, Miyagi-Shiohira C, Kurima K, Kobayashi N, Saitoh I, Watanabe M, et al. Islet culture/preservation before islet transplantation. Cell Med. 2015; 8: 25-29.

71. Baker M. Stem cells in culture: Defining the substrate. Nat Methods. 2011; 8: 293-297.

72. Van Der Sanden B, Dhobb M, Berger F, Wion D. Optimizing stem cell culture. J Cell Biochem. 2010; 111: 801-807.

73. Takita M, Matsumoto S, Noguchi H, Shimoda M, Chujo D, Sugimoto K, et al. One hundred human pancreatic islet isolations at Baylor Research Institute. Bayl Univ Med Cent Proc. 2010; 23: 341-348.

74. Saito T, Ise K, Sato $Y$, Gotoh M, Matsumoto S, Kenmochi T, et al. The start of an islet transplantation program in Japan. Transplant Proc. 2005; 37: 3424-3426.

75. Shapiro AM, Ricordi C, Hering BJ, Auchincloss H, Lindblad R, Robertson RP, et al. International trial of the Edmonton protocol for islet transplantation. N Engl J Med. 2006; 355: 1318-1330.

76. Held PJ, Bragg-Gresham JL, Peters T, Chertow GM, McCormick F, Roberts JP. The cost of procuring deceased donor kidneys: Evidence from OPO cost reports 2013-2017. Am J Transplant. 2020; 20: 1087-1094.

77. Health Quality Ontario. Pancreas islet transplantation for patients with type 1 diabetes mellitus: A clinical evidence review. Ont Health Technol Assess Ser. 2015; 15: 1-84.

78. Guignard A, Oberholzer J, Benhamou P, Touzet S, Bucher P, Penfornis A, et al. Cost analysis of human islet transplantation for the treatment of type 1 diabetes in the Swiss-French Consortium GRAGIL. Diabetes Care. 2004; 27: 895-900.

79. Costhelper Health. How much does a pancreas transplant cost? [Internet]. Campbell, CA: CostHelper Inc; [cited 2020 November 3rd]. Available from: https://health.costhelper.com/pancreas-transplant-cost.html.

80. Milliman Research. 2020 U.S. organ and tissue transplants. [Internet]. Seattle, WA: Millim; 2020 [cited 2021 January 6th]. Available from: https://milliman-cdn.azureedge.net//media/milliman/pdfs/articles/2020-us-organ-tissue-transplants.ashx.

81. Schive SW, Foss A, Sahraoui A, Kloster-Jensen K, Hafsahl G, Kvalheim G, et al. Cost and clinical outcome of islet transplantation in Norway 2010-2015. Clin Transplant. 2017; 31; e12871.

82. Axelrod DA, Schnitzler MA, Xiao H, Irish W, Tuttle-Newhall E, Chang S-H, et al. An economic assessment of contemporary kidney transplant practice. Am J Transplant. 2018; 18: 11681176.

83. Knoll GA, Nichol G. Dialysis, kidney transplantation, or pancreas transplantation for patients with diabetes mellitus and renal failure: A decision analysis of treatment options. J Am Soc Nephrol. 2003; 14: 500-515.

84. Long EF, Swain GW, Mangi AA. Comparative survival and cost-effectiveness of advanced therapies for end-stage heart failure. Circ Heart Fail. 2014; 7: 470-478.

85. Vasiliadis H-M, Collet J-P, Penrod JR, Ferraro P, Poirier C. A cost-effectiveness and cost-utility study of lung transplantation. J Heart Lung Transplant. 2005; 24: 1275-1283.

86. Anyanwu AC, McGuire A, Rogers CA, Murday AJ. An economic evaluation of lung transplantation. J Thorac Cardiovasc Surg. 2002; 123: 411-420.

87. Kensinger CD, Dageforde LA, Moore DE. Can donors with high donor risk indices be used costeffectively in liver transplantation in US Transplant Centers? Transpl Int. 2013; 26: 1063-1069.

88. Schwartz NR, Matrisian LM, Shrader E, Feng Z, Chari S, Roth JA. The potential costeffectiveness of a risk-based pancreatic cancer screening strategy in new-onset diabetes. J Clin 
Oncol. 2020; 38: 7017.

89. Beckwith J, Nyman JA, Flanagan B, Schrover R, Schuurman H-J. A health economic analysis of clinical islet transplantation. Clin Transplant. 2012; 26: 23-33.

90. Cookson R, McCabe C, Tsuchiya A. Public healthcare resource allocation and the rule of rescue. J Med Ethics. 2008; 34: 540-544.

91. Bottino R, Knoll MF, Knoll CA, Bertera S, Trucco MM. The future of islet transplantation is now. Front Med. 2018; 5: 202.

92. Archibald PR, Williams DJ. Using the cost-effectiveness of allogeneic islet transplantation to inform induced pluripotent stem cell-derived $\beta$-cell therapy reimbursement. Regen Med. 2015; 10: 959-973.

93. Neumann PJ, Cohen JT, Weinstein MC. Updating cost-effectiveness-the curious resilience of the $\$ 50,000-$ per-QALY threshold. N Engl J Med. 2014; 371:796-797.

94. Wallner K, Shapiro AM, Senior PA, McCabe C. Cost effectiveness and value of information analyses of islet cell transplantation in the management of "unstable" type 1 diabetes mellitus. BMC Endocr Disord. 2016; 16: 17.

95. Bandeiras C, Hwa AJ, Cabral JM, Ferreira FC, Finkelstein SN, Gabbay RA. Economics of beta-cell replacement therapy. Curr Diab Rep. 2019; $19: 75$.

96. Studer SM, Levy RD, McNeil K, Orens JB. Lung transplant outcomes: A review of survival, graft function, physiology, health-related quality of life and cost-effectiveness. Eur Respir J. 2004; 24: 674-685.

97. Altınörs N, Haberal M. The economics of organ transplantation. Handb Econ Giv Altruism Reciprocity. 2018; 16: 108-111.

98. Byrne ML, Hopkins D, Littlejohn W, Beckford R, Srinivasan P, Heaton N, et al. Outcomes for adults with type 1 diabetes referred with severe hypoglycaemia and/or referred for islet transplantation to a specialist hypoglycaemia service. Horm Metab Res. 2015; 47: 9-15.

99. Organ Procurement and Transplantation Network. National Data - OPTN - waitlist additions [Internet]. [cited 2020 October 16th]. Available from: https://optn.transplant.hrsa.gov/data/view-data-reports/national-data/\#.

100. Organ Procurement and Transplantation Network. National Data - OPTN - kidney wait list [Internet]. OPTN -patients on waitlist for kidney. [cited 2020 December 11st]. Available from: https://optn.transplant.hrsa.gov/data/view-data-reports/national-data/.

101. Cooper DK, Bottino R. Recent advances in understanding xenotransplantation: Implications for the clinic. Expert Rev Clin Immunol. 2015; 11: 1379-1390.

102.Cooper DK, Hara H, Iwase H, Yamamoto T, Li Q, Ezzelarab M, et al. Justification of specific genetic modifications in pigs for clinical organ xenotransplantation. Xenotransplantation. 2019; 26: e12516.

103. Cooper DK. Early clinical xenotransplantation experiences-an interview with Thomas E. Starzl, MD, PhD. Xenotransplantation. 2017; 24: e12306.

104.Phelps CJ, Koike C, Vaught TD, Boone J, Wells KD, Chen SH, et al. Production of alpha 1,3galactosyltransferase-deficient pigs. Science. 2003; 299: 411-414.

105. Bertera S, Knoll MF, Knoll CA, Cooper DK, Trucco M, Bottino R. Pig-to-macaque islet xenotransplantation. Xenotransplantation. 2020; 2110: 289-314.

106. Bottino R, Wijkstrom M, van der Windt DJ, Hara H, Ezzelarab M, Murase N, et al. Pig-tomonkey islet xenotransplantation using multi-transgenic pigs. Am J Transplant. 2014; 14: 
2275-2287.

107.van der Windt DJ, Bottino R, Casu A, Campanile N, Smetanka C, He J, et al. Long-term controlled normoglycemia in diabetic non-human primates after transplantation with hCD46 transgenic porcine islets. Am J Transplant. 2009; 9: 2716-2726.

108. Shin J-S, Kim J-M, Min B-H, Yoon IH, Kim HJ, Kim J-S, et al. Pre-clinical results in pig-to-nonhuman primate islet xenotransplantation using anti-CD40 antibody (2C10R4)-based immunosuppression. Xenotransplantation. 2018; 25: e12356.

109. Bottino R, Knoll MF, Graeme-Wilson J, Klein EC, Ayares D, Trucco M, et al. Safe use of antiCD154 monoclonal antibody in pig islet xenotransplantation in monkeys. Xenotransplantation. 2017; 24: e12283.

110.Groth CG, Korsgren O, Tibell A, Tollemar J, Möller E, Bolinder J, et al. Transplantation of porcine fetal pancreas to diabetic patients. Lancet Lond Engl. 1994; 344: 1402-1404.

111. Valdés-González RA, Dorantes LM, Garibay GN, Bracho-Blanchet E, Mendez AJ, Dávila-Pérez R, et al. Xenotransplantation of porcine neonatal islets of Langerhans and Sertoli cells: A 4-year study. Eur J Endocrinol. 2005; 153: 419-427.

112. Morozov VA, Wynyard S, Matsumoto S, Abalovich A, Denner J, Elliott R. No PERV transmission during a clinical trial of pig islet cell transplantation. Virus Res. 2017; 227: 34-40.

113. Rood PP, Cooper DK. Islet xenotransplantation: Are we really ready for clinical trials? Am J Transplant. 2006; 6: 1269-1274.

114. Cooper DKC, Matsumoto S, Abalovich A, Itoh T, Mourad NI, Gianello PR, et al. Progress in clinical encapsulated islet xenotransplantation. Transplantation. 2016; 100: 2301-2308.

115. Yang L, Güell M, Niu D, George H, Lesha E, Grishin D, et al. Genome-wide inactivation of porcine endogenous retroviruses (PERVs). Science. 2015; 350: 1101-1104.

116. Cooper DKC. Financial support for xenotransplantation research. Xenotransplantation. 2019; 26: e12483.

117. Witkowski P, Philipson L, Kaufman DB, Ratner L, Abouljoud MS, Bellin M, et al. The demise of islet allotransplantation in the US: A call for an urgent regulatory update the "islets for us" collaborative. Am J Transplant. 2020. Doi: 10.1111/ajt.16397.

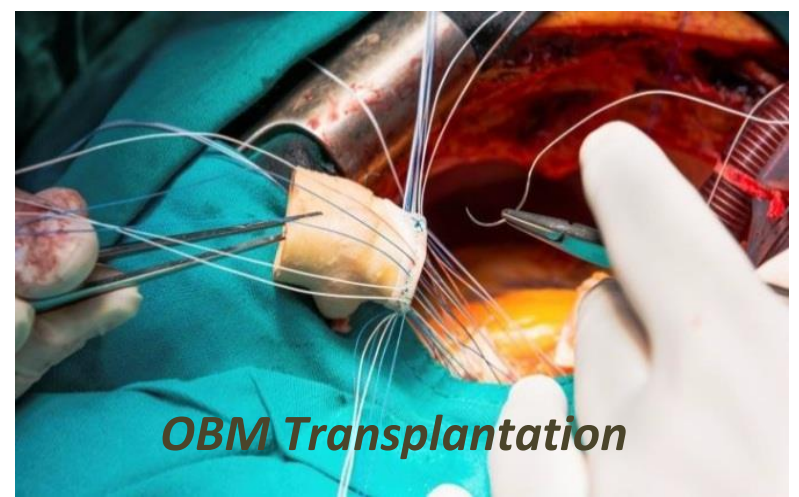

Enjoy OBM Transplantation by:

1. Submitting a manuscript

2. Joining in volunteer reviewer bank

3. Joining Editorial Board

4. Guest editing a special issue

For more details, please visit:

http://www.lidsen.com/journals/transplantation 